\title{
PENGARUH GAYA HIDUP DAN MOTIVASI TERHADAP KEPUTUSAN MENJADI MAHASISWA
}

\author{
Daniel \\ Universitas Bina Sarana Informatika \\ Email: daniel.del@bsi.ac.id
}

\begin{abstract}
Abstrak
Tujuan penelitian ini adalah untuk mengetahui korelasi antara motivasi dan gaya hidup terhadap keputusan menjadi seorang mahasiswa di perguruan tinggi. Metode penelitian yang digunakan adalah metode kuantitatif dengan teknik pengumpulan berupa pembagian kuesioner. Hasil penelitian menemukan bahwa terdapat pengaruh yang positif dan signifikan antara gaya hidup dan motivasi terhadap keputusan menjadi mahasiswa.
\end{abstract}

Kata Kunci: Motivasi, Gaya Hidup, Mahasiswa.

\section{Abstract}

The purpose of this study was to determine the correlation between motivation and lifestyle on the decision to become a student at a university. The research method used is a quantitative method with a collection technique in the form of distributing questionnaires. The results of the study found that there was a positive and significant influence between lifestyle and motivation on the decision to become a student.

Keywords: Motivation, Lifestyle, Students.

\section{A. PENDAHULUAN}

Dalam membawa suatu perubahan pada sebuah bangsa, pendidikan tinggi menjadi salah satu pilar penting. Dunia pendidikan tinggi tidak hanya dapat menjadi sarana bagi peningkatan kualitas sumber daya manusia, tetapi proses pembelajaran di kampus juga diharapkan dapat menjadi wahana yang sangat penting untuk merubah pola pikir masyarakat sipil yang demokratis. Dalam rangka persaingan global dan berbagai tantangan baik pada tingkat nasional maupun internasional, kebijakan dalam bidang pendidikan tinggi harus dapat merespon hal tersebut. Kebutuhan terhadap lulusan perguruan tinggi yang mampu bersaing dalam iklim kompetisi bisnis yang semakin kompleks, merupakan konsekuensi logis dari timbulnya persaingan di tingkat lokal maupun global.

Pendidikan merupakan hal yang terpenting dalam kehidupan berbangsa dan bernegara, berarti setiap warga negara berhak mendapat dan berharap untuk selalu berkembang dalam pendidikan. Pendidikan dipercaya sebagai alat strategis meningkatkan taraf hidup manusia. Melalui pendidikan, manusia menjadi cerdas, memiliki kemampuan atau skill, sikap hidup yang baik, sehingga dapat bergaul dengan baik di masyarakat. Pendidikan menjadi investasi yang memberi keuntungan social dan personal yang menjadikan bangsa bermartabat dan individunya menjadi manusia yang memiliki derajat (Engkoswara \& Komariah, 2010). Menurut UNESCO (United Nations, Educational, Scientific and Cultural Organization) dalam upaya meningkatkan kualitas suatu bangsa, tidak ada cara lain kecuali melalui peningkatan mutu pendidikan. UNESCO mencanangkan empat pilar pendidikan baik 
untuk masa sekarang maupun untuk masa depan, yakni: (1) learning to know (penguasaan yang dalam dan luas pada bidang ilmu tertentu), (2) learning to do (belajar untuk mengaplikasikan ilmu, berkerjasama dalam team, belajar memecahkan masalah dalam berbagai situasi, belajar berkarya atau mengaplikasikan ilmu yang didapat oleh siswa), (3) learning to be (belajar untuk dapat mandiri, menjadi orang yang bertanggung jawab untuk mewujudkan tujuan bersama), (4) learning to live together (belajar memahami dan menghargai orang lain, sejarah dan nilai-nilai agamanya) (Ekiyanto, Anita \& Suryani, 2013). Menjadi orang yang terdidik itu sangat penting. Secara umum pendidikan memiliki arti suatu proses kehidupan dalam mengembangkan diri bagi tiap individu untuk dapat hidup dan melangsungkan kehidupan.

Pendidikan formal sekarang ini menjadi sesuatu yang sangat dibutuhkan terutama untuk tingkat pendidikan tinggi dan itu juga menjadi kebutuhan kaum muda. Di tambah lagi sekarang ini tuntutan dunia kerja menuntut pendidikan tinggi atau lulus sarjana. Kaum muda saat ini semakin sadar akan pentingnya pendidikan sehingga dapat kita lihat dari tahun ketahun minat untuk memasuki perguruan tinggi meningkat mulai umur 19-24 tahun, ini membuktikan bahwa kaum muda sudah sadar akan pentingnya ilmu, ilmu pengetahuan merupakan suatu hal yang sangat urgent dalam kehidupan berbangsa dan bertanah air (BPS, 2014). Sehingga suatu bangsa atau negara dapat menghasilkan sumber daya manusia yang berkualitas dan mampu bersaing dengan bangsa atau negara lain. Secara teoritis, pendidikan yang tinggi punya tujuan buat mendidik mahasiswa dengan ilmu-ilmu dasar atau keahlian yang memadai sekaligus membantu mengenal "dunia nyata", baik melalu program terintegrasi (dalam kelas, penelitian, skripsi) atau dalam bentuk field experience (kerja praktek/magang) (UU Nomor 12 Tahun 2012). Perguruan tinggi memberikan gelar untuk mahasiswanya, dan berorientasi pada pembentukan insan yang profesional dan memiliki standar ilmu yang cukup.

Komunikasi merupakan hal yang mendasar dan penting dalam hubungan apapun. Membangun dan mengelola hubungan dengan konsumen dan pelanggan memiliki pengaruh langsung pada komunikasi pemasaran. Komunikasi pemasaran (marketing communication) membantu mendefinisikan hubungan produsen dengan konsumen tidak hanya pesan yang dipertukarkan tetapi juga pilihan media dan kesempatan yang sesuai dengan keinginan pelanggan mereka. Alma (2008) dalam bukunya menulis perguruan tinggi swasta yang ingin sukses untuk masa depan, dalam menghadapi bagaimana mencari jumlah mahasiswa yang dikehendaki harus mempraktekkan komunikasi pemasaran secara terintegrasi. Alma (2008) juga mengutip Chapman: "As a solution to this enrollment problem, many universities have begun to turn to marketing approaches and technigues to help strengthen and more fully understand the demand side of the enrollment picture."

\section{B. TINJAUN PUSTAKA}

Di dalam bukunya Kotler (2011) mengatakan: "Marketing communication are the means by which firms attempt to inform, persuade, and remind consumers directly or inderectly about the products and brands they sell. In a sense, marketing communications represent the voice of the company and its brands; they a means by which the firm can establish a dialogue and build relationship with consumers". 
Komunikasi pemasaran merupakan sarana perusahaan untuk menginformasikan, membujuk dan mengingatkan konsumen secara langsung atau tidak langsung tentang produk dan merek yang mereka jual. Dengan kata lain, komunikasi pemasaran mewakili perusahaan dan brand itu sendiri; dimana komunikasi pemasaran menjadi sarana perusahaan untuk membangun dialog dan hubungan dengan para konsumen. Marketing communication juga dapat dinyatakan sebagai kegiatan komunikasi yang bertujuan untuk menyampaikan pesan pada konsumen dengan menggunakan berbagai media (Kennedy \& Soemanagara, 2010). Chris (2009), menulis dalam perencanaan marketing communication mengandung tiga unsur: tools (alat), media dan messages (pesan). Tools utama marketing communication: iklan (advertising), promosi penjualan (sales promotion), public relations, penjualan langsung (direct marketing), penjualan personal (personal selling) (Chris, 2009). Selain itu ada media atau sarana dimana pesan iklan dan komunikasi pemasaran disampaikan. Alat dan media memiliki karakteristik dan pencapian gol yang berbeda. Perguruan tinggi harus tahu bagaimana menggunakan iklan, promosi penjualan, publisitas, penjualan langsung dan penjualan personal untuk mengkomunikasikan suatu produk jasa pendidikannya beserta nilainya kepada calon mahasiswa sesuai dengan target yang ingin di tuju. Bentuk komunikasi yang disusun harus inovatif dan estetis sehingga lebih mudah diingat dan memiliki pembeda dengan bentuk promosi lainnya. Setelah itu pelanggan harus merasa feel good sehingga dapat menimbulkan pikiran dan opini yang positif.

\section{METODE}

Metode penelitian yang digunakan oleh penulis sesuai dengan tujuan penelitian, maka peneliti menggunakan metode penelitian eksplanatif dengan pendekatan kuantitatif. Menurut Sugiyono (2008) metode eksplanatif adalah metode explanatory survey merupakan metode penelitian yang dilakukan pada populasi besar maupun kecil, tetapi data yang dipelajari adalah data yang diambil dari sampel populasi tersebut, sehingga ditemukan dekripsi dan hubungan-hubungan antar Variabel. Sedangkan metode kuantitatif masih menurut Sugiyono (2008) merupakan metode penelitian berlandaskan pada filsafat positivisme, digunakan untuk meneliti pada populasi atau sample tertentu, pengumpulan data menggunakan instrument peneliltian, analisis data bersifat kuantitatif atu statistik, dengan tujuan menguji hipotesis yang telah ditetapkan. Tujuan dari metode eksplanatif kuantitatif ini yaitu membuat uraian yang sistematis mengenai fakta-fakta dari objek yang diteliti kemudian menggabungkan hubungan antar variabel yang telibat didalamnya.

Penelitian ini digunakan untuk menguji variabel $\mathrm{X}_{1}, \mathrm{X}_{2}$ terhadap $\mathrm{Y}$ yang diteliti. Kegiatan penelitian ini didasarkan pada ciri-ciri keilmuan yang rasional, empiris dan sistematis guna memperoleh data-data tepat sehingga dapat dijadikan sebagai sebuah informasi yang penting dan berguna dalam proses penyusunan suatu penelitian. Data yang dibutuhkan merupakan data yang sesuai dengan masalah-masalah yang ada dan dengan tujuan penelitian, sehingga data tersebut akan dikumpulkan, dianalisis dan diproses lebih lanjut sesuai dengan teori-teori yang telah dipelajari, jadi dari data tersebut ditarik kesimpulan. Penelitian ini dimaksudkan untuk menguji hipotesis dengan menggunakan perhitungan statistik.

Berdasarkan teori-teori yang diuraikan pada bab sebelumnya, definisi koseptual dari masing-masing variabel adalah sebagai berikut: 
1. Motivasi merupakan bagian yang mendorong seorang calon mahasiswa untuk meningkatkan kualitas diri dan menyadari betapa pentingnya sebuah pendidikan. Dorongan ini dapat timbul dari faktor internal maupun faktor eksternal, sebagai sebuah kebutuhan akan aktualisasi diri. Dorongan berprestasi, dorongan berkuasa dan dorongan berafiliasi atau bersahabat.

2. Gaya hidup menjadi seorang sarjana memiliki status yang berbeda. Mahasiswa menghabiskan waktu, kesenangan dan memiliki opini pentingnya sebuah penghargaan yaitu gelar sebagai sarjana. Membuat mereka menjadi lebih percaya diri dalam lingkungan sosialnya.

3. Keputusan menjadi Mahasiswa melalui sebuah proses mengetahui apa yang menjadi kebutuhan, mendapatkan informasi, mengevaluasi pilihan alternatif hingga pada akhir melakukan pembelian, mahasiswa memutuskan untuk kuliah.

Dalam penelitian ini perlu diketahui operasional konsep dari setiap variabel untuk menghindari ketidak jelasan arti variabel-variabel yang akan diteliti. Operasional konsep dari variabel-variabel (table 1) tersebut dinyatakan sebagai berikut:

1. Motivasi (variabel $\mathrm{X}_{1}$ )

2. Gaya hidup (variabel $\mathrm{X}_{2}$ )

3. Keputusan menjadi Mahasiswa (variabel $\mathrm{Y}_{1}$ )

Tabel 1 Operasional Konsep

\begin{tabular}{|c|c|c|c|c|}
\hline Konsep & Variabel & Dimensi & Indikator & $\begin{array}{c}\text { Skala } \\
\text { Pengungkuran }\end{array}$ \\
\hline \multirow{8}{*}{ 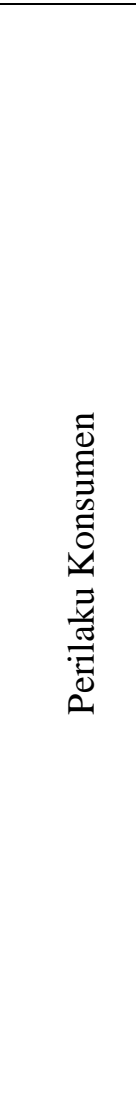 } & \multirow[t]{3}{*}{ Motivasi } & n-Ach & $\begin{array}{l}\text { - Dorongan menjadi yang } \\
\text { terbaik } \\
\text { - Dorongan mencapai } \\
\text { keberhasilan } \\
\text { - Dorongan berjuang untuk } \\
\text { sukses. }\end{array}$ & Likert \\
\hline & & n-Pow & $\begin{array}{l}\text { Dorongan untuk menduduki } \\
\text { posisi penting dalam pekerjaan }\end{array}$ & Likert \\
\hline & & n-Affil & $\begin{array}{l}\text { Dorongan untuk menjalin } \\
\text { hubungan sosial dan bersahabat }\end{array}$ & Likert \\
\hline & \multirow{3}{*}{$\begin{array}{l}\text { Gaya } \\
\text { hidup }\end{array}$} & Activity & $\begin{array}{l}\text { Menghabiskan waktu untuk } \\
\text { menjalankan yang disukai }\end{array}$ & Likert \\
\hline & & Interest & $\begin{array}{l}\text { - Tertarik untuk kuliah sambil } \\
\text { kerja. } \\
\text { - Pengunaan system digital }\end{array}$ & Likert \\
\hline & & Opinion & $\begin{array}{l}\text { Menjadi Sarjana menambah } \\
\text { rasa percaya diri dalam } \\
\text { lingkungan sosial }\end{array}$ & Likert \\
\hline & \multirow[t]{2}{*}{$\begin{array}{l}\text { Keputusan } \\
\text { Pembelian }\end{array}$} & $\begin{array}{l}\text { Evaluation of } \\
\text { alternative }\end{array}$ & $\begin{array}{l}\text { - Kemudahan memperoleh } \\
\text { informasi. } \\
\text { - Melakukan evaluasi terhadap } \\
\text { alternative yang ada. }\end{array}$ & Likert \\
\hline & & Purchase & $\begin{array}{l}\text { Memutuskan untuk melakukan } \\
\text { pembelian. }\end{array}$ & Likert \\
\hline
\end{tabular}

Sumber: Pengolahan data primer (Tahun 2014) 


\section{Uji Validasi}

Validasi adalah derajat ketepatan antara data yang sesungguhnya terjadi pada obyek penelitian dengan data yang dapat dilaporkan oleh peneliti (Sugiyono, 2008). Sedangkan Simamora (2004) berpendapat bahwa validitas adalah suatu ukuran yang menunjukkan tingkat kevalidan atau kesahihan suatu instrumen dianggap valid apabila mampu mengukur apa yang diinginkan. Pengujian validitas digunakan untuk mengukur setiap butir pernyataan atau pertanyaan dalam kuesioner digunakan analisa item, yaitu mengkorelasikan skor setiap butir item dengan skor totalnya, dengan rumus korelasi Product Moment Pearson dengan Level signifikasi $5 \%=0,05$.

\section{Uji Reliabilitas}

Menurut Sugiyono (2008), realibilitas adalah derajat konsistensi dan stabilitas data atau temuan. Simamora (2004) berpendapat bahwa, reliabilitas adalah tingkat keandalan kuesioner. Kuesioner yang reliabel atau handal kuesioner yang apabila dicobakan secara berulang-ulang kepada kelompok yang sama akan menghasilkan data yang sama. Instrumen dapat dikatakan reliabel jika perhitungan validitas lebih besar dari nilai kritisnya pada taraf signifikan 0,05 $(\mathrm{a}=5 \%)$ dan dengan menggunakan uji Cronbach Alpha, suatu variabel dikatakan reliabel jika nilai Cronbach Alpha lebih besar dari 0,60.

\section{Teknik Pengumpulan Data}

Dalam penelitian ini data yang digunakan oleh peneliti merupakan data yang bersifat kuantitatif karena dinyatakan dengan angka-angka yang menunjukkan nilai terhadap besaran atas variabel yang mewakilinya. Jenis data yang digunakan dalam penelitian ini yaitu data primer dan data sekunder.

\section{Data Primer}

Merupakan data yang diperoleh secara langsung dari objek yang diteliti. Sugiono (2008) menyatakan bahwa: "Sumber primer adalah sumber data yang langsung memberikan data kepada pengumpul data". Data primer yang diperoleh dengan cara menggunakan angket dengan para mahasiswa kelas PKK Universitas Mercu Buana - Menteng, Jakarta pusat. Fakultas Ilmu Komunikasi, Ekonomi \& Bisnis, Ilmu Komputer dan Pasca Sarjana angkatan tahun 2005-2006 yang tercatat sebagai mahasiswa aktif.

\section{Data Sekunder}

Menurut Sugiono (2008) pengertian dari data sekunder adalah "Sumber data yang tidak langsung memberikan data kepada pengumpul data, misalnya lewat orang atau lewat dokumen". Data sekunder antara lain disajikan dalam bentuk data-data, tabel-tabel, diagramdiagram atau mengenai topik penelitian. Data ini merupakan data yang berhubungan secara langsung dengan penelitian yang dilaksanakan dan bersumber dari Universitas Mercu Buana yaitu, gambaran umum objek penelitian, visi dan misi, struktur organisasi, data mahasiswa aktif kelas karyawan kampus B Menteng 2005-2006. Hasil searching di internet menenai artikel-artikel, dan jurnal yang digunakan peneliti sebagai bahan penelitian yang dilakukan. 


\section{Teknik Analisa Data}

Berdasarkan jenis data yang telah diperoleh pada penelitian ini maka teknik atau analisa data yang dipergunakan adalah data kuantitatif yaitu dengan mengolah dan kemudian disajikan dalam bentuk tabel untuk dipresentasikan hasil perolehan data kemudian dianalisis dengan menggunakan teknik eksplanasi dan presentasi. Adapun langkah-langkah yang dilakukan:

\section{Editing}

Editing yaitu menggedit jawaban bila mana ada para mahasiswa yang mengisi kuesioner yang diberikan oleh peneliti terlewatkan dengan kata lain jawaban yang diberikan tidak lengkap. Kuesioner/angket adalah daftar pertanyaan tertulis yang memerlukan tanggapan baik kesesuaian maupun ketidaksesuaian dari sikap testi (Kasmadi \& Siti, 2013). Dalam hal ini, peneliti memberikan kuesioner kepada 318 responden dari Universitas Mercu Buana Menteng Jakarta Pusat.

2. Coding

Coding adalah upaya memilah-milah setiap satuan data ke dalam bagian-bagian yang memiliki kesamaan (Rahmadi \& Moleong, 2011). Dalam penelitian ini Pengukuran tingkat persetujuan menggunakan skala yang dikembangkan dari skala Likert yang merupakan skala interval (Sekaran, 2006). Skala dalam penelitian ini menggunakan 5 poin skala yang diberikan bobot nilai, seperti dalam tabel 2 berikut ini:

\section{Tabel 2 Skala Likert}

\begin{tabular}{|c|c|}
\hline Jawaban & Nilai \\
\hline Sangat Setuju & 5 \\
\hline Setuju & 4 \\
\hline Netral & 3 \\
\hline Tidak Setuju & 2 \\
\hline Sangat Tidak Setuju & 1 \\
\hline
\end{tabular}

Sumber: Sekaran (2006)

\section{HASIL DAN PEMBAHASAN}

Annalisis statistik dibagi menjadi beberapa tahap yang akan dijelaskan sebagai berikut:

1. Uji Validitas

Sebelum menyebarkan kuesioner yang sesungguhnya peneliti terlebih dahulu melakukan analisis validitas. Dengan menggunakan rumus korelasi product moment dibantu dengan program SPSS 17.0. Pernyataan dinyatakan valid dengan cara membandingkan $r$ (korelasi) hitung dengan $r$ tabel dimana $r$ tabel dari signifikansi 5\% dan jumlah responden (n) 25 orang yaitu: 0.396. Kriteria valid atau tidak, harus membandingkan nilai $r$ hitung pada tiap-tiap pernyataan harus lebih besar dari $r$ tabel (P01 $r_{\text {hitung }}>r_{\text {tabel }}$, selengkapnya dapat kita lihat pada tabel 3 berikut:

\section{Tabel 3 Uji Validitas}

\begin{tabular}{|c|c|c|c|}
\hline Pernyataan & $\mathbf{r}$ hitung & $\mathbf{r}$ tabel & Keterangan \\
\hline P01 & 0.510 & 0.396 & Valid \\
\hline P02 & 0.434 & 0.396 & Valid \\
\hline P03 & 0.433 & 0.396 & Valid \\
\hline P04 & 0.478 & 0.396 & Valid \\
\hline
\end{tabular}


ARTIKEL

\begin{tabular}{|l|l|l|l|}
\hline P05 & 0.528 & 0.396 & Valid \\
\hline P06 & 0.553 & 0.396 & Valid \\
\hline P07 & 0.636 & 0.396 & Valid \\
\hline P08 & 0.645 & 0.396 & Valid \\
\hline P09 & 0.650 & 0.396 & Valid \\
\hline P10 & 0.691 & 0.396 & Valid \\
\hline P11 & 0.649 & 0.396 & Valid \\
\hline P12 & 0.463 & 0.396 & Valid \\
\hline P13 & 0.562 & 0.396 & Valid \\
\hline P14 & 0.496 & 0.396 & Valid \\
\hline P15 & 0.620 & 0.396 & Valid \\
\hline
\end{tabular}

Sumber: Pengolahan dengan SPSS 17.0 (Tahun 2014)

\section{Uji Reabilitas}

Selain dilakukan uji validitas, instrument penelitian yang berupa kuesioner juga diuji reliabilitasnya. Hasil uji reliabilitas dapat dikatakan reliabel jika perhitungan validitas lebih besar dari nilai kritisnya pada taraf signifikan 0,05 $(\mathrm{a}=5 \%)$ dan dengan menggunakan uji Cronbach Alpha, suatu variabel dikatakan reliabel jika nilai Cronbach Alpha lebih besar dari 0,60. Dari tabel perhitungan dengan menggunakan bantuan SPSS 17. 0 dapat diketahui bahwa nilai Cronbanh's Alpha sebesar 0.897. Dikatakan reliabel karena nilainya lebih besar dari $0.60(0.897>0.60)$.

\begin{tabular}{|r|r|}
\hline Tabel 4 Uji Reliability Statistics \\
\hline Cronbach's Alpha & N of Items \\
\hline .888 & 15 \\
\hline
\end{tabular}

\section{Uji Korelasi dan Regresi}

Kemudian langkah berikutnya adalah menggunakan korelasi Pearson Product Moment untuk mengetahui derajat hubungan dan kontribusi masing-masing variabel bebas terhadap variabel terikat. Kemudian untuk mencari besarnya hubungan dan kontribusi dua variable bebas atau lebih secara simultan (bersama-sama) dengan varibel terikat digunakan analisis multiple correlation (Riduwan \& Sunarto, 2007).

Rumus Korelasi Ganda:

$$
R_{y x_{1} x_{2}}=\sqrt{\frac{r_{y x_{1}}^{2}+r_{y x_{2}}^{2}-2 r_{y x_{1}} r_{y x_{2}} r_{x_{1} x_{2}}}{1-r_{x_{1} x_{2}}^{2}}}
$$

Dimana:

$\mathrm{R}_{\mathrm{yx} 1 \times 2}=$ Nilai koefisien korelasi ganda antara varabel $\mathrm{X}_{1}$ dan $\mathrm{X}_{2}$

$\mathrm{r}_{\mathrm{yx} 1}=$ Koefisien korelasi $\mathrm{X}_{1}$ terhadap $\mathrm{Y}$

$\mathrm{r}_{\mathrm{yx} 2}=$ Koefisien korelasi $\mathrm{X}_{2}$ terhadap $\mathrm{Y}$

$\mathrm{r}_{\mathrm{x} 1 \times 2}=$ Koefisien korelasi $\mathrm{X}_{1}$ terhadap $\mathrm{X}_{2}$

Korelasi bilangan yang menyatakan kuat dan rendah hubungan disebut koefisien hubungan atau koefisien korelasi. Koefisien korelasi itu berkisar antara -0.00 dan +1.00 (korelasi positif) dan atau diantara 0.00 sampai -1.00 (korelasi negative), tergantung pada arah hubungan positif atau negatif. Koefisien yang bertanda positif menunjukkan bahwa arah 
korelasi tersebut positif, dan koefisien bertanda negative menunjukkan arah korelasi yang negative. Sedangkan koefisien yang bernilai 0.00 menunjukkan tidak adanya korelasi antara variabel $\mathrm{X}$ dan $\mathrm{Y}$.

Bila mana dua variabel mempunyai keofisien korelasi, sebesar +1.00 maka berarti bahwa dua variabel tersebut mempunyai korelasi positif yang sempurna. Sebaliknya bilamana dua variabel tersebut mempunyai koefisien korelasi -1.00 , maka berarti dua variabel tersebut memiliki korelasi negatif yang sempurna. Korelasi yang sempurna semacam itu sangat jarang sekali dijumpai dalam praktik penyelidikan/penelitian. Korelasi antara dua variabel pada umumnya akan berkisar antara +1.00 sampai dengan -1.00 seperti terdapat pada tabel 5 .

\section{Tabel 5 Acuan Interpretasi Koefisien Korelasi}

\begin{tabular}{|c|c|}
\hline Interval Koefisien & Tingkat Hubungan \\
\hline $0.00-0.199$ & Sangat Rendah \\
\hline $0.20-0.399$ & Rendah \\
\hline $0.40-0.599$ & Sedang \\
\hline $0.60-0.799$ & Kuat \\
\hline $0.80-1.000$ & Sangat Kuat \\
\hline
\end{tabular}

Sumber: Kasmadi dan Sunariah (2013)

Karena peneliti menggunakan variabel independen lebih dari satu dengan satu variabel dependen maka menurut Trihendradi (2009) dilakukan uji regresi linear berganda untuk meramalkan suatu variabel dependen (keputusan menjadi mahasiswa) berdasar atau lebih variabel independen (motivasi dan gaya hidup), dalam suatu persamaan linear. Rumus persamaan regresi ganda, sebagai berikut:

$$
\begin{aligned}
& \hat{\mathrm{Y}}=\mathrm{a}+\mathrm{b} 1 \mathrm{X}_{1}+\mathrm{b} 2 \mathrm{X}_{2}+\ldots+\mathrm{b}_{\mathrm{n}} \mathrm{X}_{\mathrm{n}} \\
& \mathrm{Y}=\text { Variabel terikat } \\
& \mathrm{a}=\text { Konstanta } \\
& \mathrm{b}_{1}, \mathrm{~b}_{2}=\text { Koefisien regresi } \\
& \mathrm{X}_{1}, \mathrm{X}_{2}=\text { variabel bebas }
\end{aligned}
$$

\section{E. KESIMPULAN}

Terdapat pengaruh motivasi dan gaya hidup yang positif dan signifikan terhadap keputusan menjadi mahasiswa Universitas Mercu Buana. Ketika salah satu variabel independen dikontrol motivasi dan gaya hidup bukanlah faktor untama yang mempengaruhi keputusan menjadi mahasiswa di Universitas Mercu Buana kelas PKK - Menteng. Secara parsial motivasi dan gaya hidup memiliki pengaruh rendah terhadap variabel keputusan menjadi mahasiswa. Hasil analisis statistik dengan uji regresi berganda dari uji motivasi dan gaya hidup terhadap keputusan menjadi mahasiswa didapatkan motivasi dan gaya hidup memiliki pengaruh sebesar $25.5 \%$ sedangkan presentasi selebihnya di pengaruhi oleh variabel lain diluar dari penelitian ini.

\section{DAFTAR PUSTAKA}

Ajar \& Steven. (2006). Motivasiholic. Jakarta: Grasindo.

Alma, B., \& Hurriyati, R. (2008). Manajemen Corporate \& Strategi Pemasaran Jasa Pendidikan. Bandung: Alfabeta. 
Assael, H. (1984). Consumer Behavior and Marketing Action. 2nd. Boston: Kent Publising Company.

Belch, G. E., \& Belch, M. A. (2007). Advertising and Promotion: An Integrated. Marketing Communication Perspective. New York: Mc-Graw Hill.

Durianto, D., Sugiarto, \& Sitinjak, T. (2001). Strategi Menaklukan Pasar Melalui Riset Ekuitas dan Perilaku Merek. Jakarta: Gramedia Pustaka Utama.

Engkoswara \& Komariah, A. (2010). Administrasi Pendidikan. Bandung: Alfabeta.

Fill, C. (2009). Marketing Communication Interactivity, Communities and Content. England: Pearson Education.

Ginting, J. E. D., \& Sianturi, B. O. (2005). Pengambilan Keputusan Membeli Ditinjau dari Gaya Hidup Value-Minded. Psikologia I.

Hawkins, M. B. (2007). Consumer Behavior. New York: Mc-Graw Hill.

Jushermi. (2013). Analisis Segmentasi Gaya Hidup pada Mahasiswa Jurusan Manajemen S1 Fakultas Ekonomi. Ekonomi, 21(1).

Kasmadi, \& Sunariah, N. S. (2013). Panduan Modern Penelitian Kuantitatif. Bandung: Alfabeta.

Kennedy, J., \& Soemanagara, R. D. (2009). Marketing Comunication. Jakarta: Bhuana Ilmu Populer. 